\title{
VARIANT ABDUCTOR POLLICIS LONGUS MUSCLE: A CASE REPORT
}

\begin{abstract}
Shipra Paul', Srijit Das ${ }^{2}$
Maulana Azad Medical College, New Delhi, India: Department of Anatomy'; University Kebangsaan, National University of Malaysia, Kuala Lumpur, Malaysia: Department of Anatomy ${ }^{2}$

Summary: Abductor pollicis longus (APL) muscle is known to exhibit different variations with respect to its attachments. Various studies have reported the splitting of the APL muscle. Comparative anatomical findings of split insertion of APL is commonly found in chimpanzees, gorillas and gibbons. In the present study, we describe an anomalous APL muscle, which originated from the posterior surface of the shaft of the radius and ulna and traversed a course deep to the extensor retinaculum. Interestingly, immediately after emerging form the deeper aspect of extensor retinaculum, the thin tendon of the APL muscle continued again as a muscular belly in relation to the dorsolateral part of the $1^{\text {st }}$ metacarpal bone, to end as a tendon with its attachment to the base of the proximal phalanx. Such an unusual variation of APL with its attachment into proximal phalanx is a rare finding and may be of importance in altering the mechanics of the thumb during abduction. The clinical significance of such an anatomical variation of APL may be important during reconstructive surgeries involving thumb and also of academic interest.
\end{abstract}

Key words: Variation; Anomaly; Muscle; Abductor pollicis longus; Tendon; Attachment

\section{Introduction}

Several research studies have highlighted the anomalies involving the APL muscle. There are reports on the anomalous division of APL into varying number of slips. One such report even defined the APL to divide into seven different slips. It has been defined that "It may be exceptional to find a single tendon of insertion of this muscle" (4). Past reports have outlined the fact that much has been known about the tendons of APL but there are few reports on the muscle bellies of APL (16).

In the present study, the APL muscle after originating from the posterior surface of the radius and the ulna, continued as a tendon under the extensor retinaculum, thereafter became a muscle belly in relation to dorsolateral aspect of Ist metacarpal bone and descended distally as a tendon to insert into the base of proximal phalanx. Such an anomaly assumes great clinical significance considering the fact that the usual attachment of the APL is on the base of the first metacarpal bone or the trapezium bone (13). This anomalous pattern of APL may alter the mechanism for thumb movements.

The anomalies of APL often remain undetected in normal life in absence of symptoms and are incidental findings in autopsies or cadaveric dissections. Knowledge of such anomalous APL may also be important for tendon transfers, tendon translocation and interposition arthroplasty, where the APL tendon is harvested (6). We as anatomists believe that reporting such important variations of APL may be important for clinicians and surgeons in day to day practice.

\section{Case report}

During routine cadaveric dissection in the department of anatomy, we detected anomalous APL muscle on both

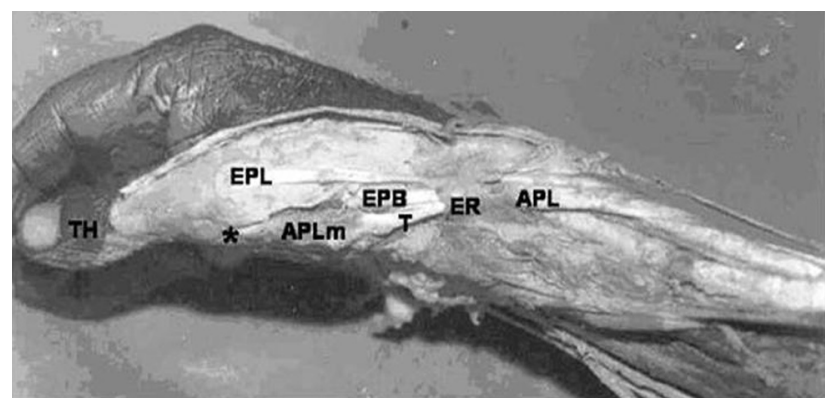

Fig. 1: Photograph of dissected specimen showing:

APL - APL muscle before crossing ER to enter hand; APLm - Abductor pollicis longus muscle; ER - Extensor retinaculum; T - Tendon of abductor pollicis longus becoming a muscle belly related to Ist metacarpal bone.; EPB Extensor pollicis brevis muscle; EPL - Extensor pollicis longus muscle; $\mathrm{TH}$ - Thumb

The asterix (*) shows the insertion of the APL muscle. 
sides of a 34 year male cadaver with history of cardiac arrest. The extensor and the lateral compartment of the hand were dissected and the APL muscle was displayed. The variations of the APL were noted on both upper limbs. The muscle was studied in detail and appropriate photograph was taken (Fig. 1).

\section{Observations (Fig. 1)}

The APL muscle originated from the posterior surface of the radius and ulna. Soon after its origin the muscle descended laterally. The tendon of APL muscle continued beneath the extensor retinaculum, to continue as a muscle belly in relation to dorsolateral aspect of the $1^{\text {st }}$ metacarpal bone before its final insertion again as a tendon into the base of proximal phalanx. The tendon of extensor pollicis brevis accompanied the APL tendon. The extensor pollicis brevis had its normal attachment accompanying the APL in the same compartment. This anomaly was noted on both sides of the cadaver. No other associated anomalies were observed.

\section{Discussion}

Split insertion of APL is commonly found in chimpanzees, gorillas and gibbons (15). This fact had prompted many of the past researchers to focus their study on the APL muscle. The APL is widely considered to be the most variable muscle in the forearm (5). The anomalies of the APL assumes much importance for any academic, surgical and clinical purpose considering the fact that there are less reports of such variations in standard anatomy and surgery textbooks.

Duplication of the APL muscle have been reported (1, $4,13,14)$. A varying number of tendon slips ranging from three to seven have been reported. $(2,3,9,10,11)$. From the above facts it is clear that APL exhibits more than one tendon, hence the clinical importance of the anomalous divisions of APL cannot be neglected. Although there are various reports on the variations in the number of slips of the APL tendon, to the best of our knowledge, there are hardly any studies which report the tendon of APL becoming a muscle belly and again a tendon to be inserted to the proximal phalanx instead of its normal attachment to the metacarpal. A conventional textbook has reported the fact that the muscle belly might be split into different muscular components but no further details regarding its frequency or its distal attachment into proximal phalanx have been described (13).

Presence of anomalies of APL muscle are usually detected when the patient presents with clinical symptoms. The anomalies of the APL are important to understand the etiology and subsequent surgical decompression of De Quervains Syndrome (7, 8, 14). During surgeries the unawareness of the multiple tendons in separate compart- ments may result in improper recognition of the tendons (9). There are more chances of injury during surgeries, if there is the lateral position of the supernumerary tendon (12). Supernumerary tendons contribute to the development of De Quervain's stenosing tendovaginitis.

All the past research studies have mentioned the fact of multiple tendons of APL muscle but none of the reports have defined a muscular belly which was found in relation to the metacarpal and the tendinous continuation to insert into the proximal phalanx. Our study reports a normal origin of APL but its tendon instead of inserting into the metacarpal bone became a muscle belly in relation to the dorsolateral part of the Ist metacarpal bone ('D' in Fig. 1) and again became a tendon before its distal attachment to the base of proximal phalanx. We as anatomists speculate that the existence of such an anomaly may alter the power of grip, as the thumb forms one half of the functional unit while holding or gripping an object.

The thumb is useless without the tendon of APL muscle as the metacarpo-phalangeal joint will overextend during any attempt of pincer grasp between thumb and index finger (9). The mechanics of the abduction of the thumb may be altered in such a case. In absence of any classical description of the variations of the APL muscle belly in conventional anatomy textbooks, the present case study is a humble effort to highlight anomalous muscle bellies of APL before its distal attachment to the phalanx. The knowledge of such a variation may be important in understanding the proper functioning of the thumb movements and helpful during any interposition arthroplasty where the APL tendon is used.

\section{References}

1. Baba MA. The accessory tendon of the abductor pollicis longus muscle. Anat Record 1954;119:541-6.

2. Backhouse KM. Abductor pollicis longus musculotendinous split as a replacement motor for ruptured extensor pollicis longus. Hand 1981;13:271-5.

3. Bergman RA, Thompson SA, Afifi AK, Saadeh FA. Compendium of Human Anatomic Variation: Catalog, Atlas and World Literature. Urban \& Schwarzenberg, Baltimore and Munich: 1988:16.

4. Coleman SS, DK McAffe, BJ Anson. The insertion of the abductor pollicis muscle. An anatomical study of 175 specimens. Q. Bull. Northwest. Univ. Med School 1953;27:117-22.

5. Dawson SN, Barton. Anatomical variations of the extensor pollicis brevis. J. Hand Surg 1986;11B:378-81

6. Dos Remedios C, Chapnikoff D, Wavreille G, Chantelot C, Migaud H, Fontaine $\mathrm{C}$. The abductor pollicis longus: relation between innervation, muscle bellies and number of tendinous slips. Surg Radiol Anat 2005;27:243-8.

7. Giles KW. Anatomical variations affecting the surgery of De Quervain's disease. J Bone J Surg 1960;42:352-5.

8. Jackson WT, Viegas SF, Coon TM, Stimpson KD, Frogameni AD, Simpson JM Anatomical variations in the first extensor compartment of the wrist. A clinical and anatomical study. J Bone Joint Surg [Am ] 1986;68:923-26.

9. Melling M, Wilde J, Schnallinger M, Schweighari W, Panholzer M. Supernumerary tendons of the abductor pollicis. Acta Anat 1996;155:291-4.

10. Schmidt R. Zur funktionellen und klinischen Bedeutung der accessorischen Sehnen des M.abductor pollicis longus. Verh. Anat. Ges 1987;81:319-21.

11. Schmidt HM \& Lahl J. Untersuchungen an den Sehnenfachern der Streckmuskeln ammenschlichen Handruken und ihrer Schnenscheiden. I. Gegenbaurs. Morphol. Jahrb 1988;134:155-73.

12. Schmidt R, Schultka R, Hammer R, Dorn A. Untersuchungen zur Haufigkeit accessorischer Sehnen des M. abductor pollicis longus, unter Berucksichtig- 
ung ihrer Bedeutung fur die Praxis. Gegenbaurs. Morphol. Jahrb, 112:139-149, 1968

13. Standring Susan. Gray's Anatomy $39^{\text {th }}$. ed. Elsevier Churchill Livingstone, New York: 2005:881.

14. Stein AH. Variations of the tendons of insertion of the abductor pollicis longus and the extensor pollicis brevis. Anat Rec 1951;110:49-53.
15. Thomas LH, Goldstein LA, Tobin CE. Anatomical and clinical study of the variations in the insertions of the abductor pollicis longus tendon, associated with stenosing tendovaginitis. J Bone Joint Surg [Am] 1951;33:347-50.

16. Van Oudenaarde E. The function of the abductor pollicis longus muscle as a joint stabilizer. J Hand Surg [Br] 1991;16:420-3.

Submitted June 2007.

Accepted August 2007.

\section{Corresponding author:}

Prof. Shipra Paul, MBBS, MD, FIMSA; MNAMS, D-II/A-75, Nanak Pura, Moti Bagh-South, New Delhi-110021, India, e-mail: drshipra14@yahoo.com 